\title{
O Encontro Entre o Hiperlocal e o Global no Hard News Televisivo no Canal de Notícias Norte-Americ a no NY11
}

Edua rdo RITTER 2

\section{Resumo}

Nova York é reconhecidamente uma cidade cosmopolita e multic ultural. Desde a sua fundação até a contemporaneidade, ela recebe pessoas vindas de todas as partes do mundo. No entanto, é nesse contexto global que surgiu, em 1992, o primeiro canal de notícias hiperlocal da companhia Time Wamer Cable: o New York 1. Até hoje a emissora mantém uma programação em formato hard news com notícias exclusivamente locais, envolvendo os cinco grandes bairros da cidade. A partir das reflexões sobre a proximidade geográfica como critério de notic iabilidade do telejomalismo, de apontamentos acerca da relação do local $x$ global e da contextualização histórica da cidade, é feita a análise da programação da emissora. Para tanto são fundamentais as visões de global e local de Hall (2009 e 2014), de tribalismo de Maffesoli (2005) e de critérios de notic iabilidade de Traquina (2005).

Palavras-chave: Telejomalismo. Notícia Local. Hard News.

\section{Abstract}

The New York is a recognized cosmopolitan and multic ultural city. Since New York was founded until nowadays, it gets people from all over the world. However, it is in this overall context that, in 1992, the first hyperlocal news channel was created by Time Wamer Cable Company: New York 1 . The station still maintains a schedule in hard news format with news exclusively local, involving the five major city neighborhoods. From reflections on the geographical proximity as newsworthiness criteria of television news, of notes on the relationship of the local $x$ global and

1 Trabalho apresentado no GP Telejomalismo, XV Encontro dos Grupos de Pesquisas em Comunicação, evento componente do XXXVIII Congresso Brasileiro de Ciências da Comunicação.

2 Professor Adjunto do Departamento de Ciências da Comunicação (Decom) da Universidade Federal de Santa Maria (UFSM), campus Frederico Westphalen. Doutor em Comunicação Social pelo Programa de Pósgraduação em Comunicação Social com estágio doutoral na New York University (NYU) de Nova York (Estados Unidos). Jomalista graudo pela UnijuíRS. ritterga uc ho @hotmail.com 
historical context of the city, it is made the analysis of the station's programming. For both are fundamental the global and local views of Hall (2009 and 2014), the tribalism idea of Maffesoli (2005) and newsworthiness criteria of Tra quina (2005).

Keywords: Television J oumalism. Local News. Ha rd News.

\section{Considerações iniciais}

Um dos principais critérios de noticiciabilidade do jornalismo, conforme já apontaram diversos autores, dentre os quais Traquina (2005), Luhmann (2005) e Sousa Pinto (2009), é a proximidade geográfica. Dentre todas as plataformas tradicionais de comunicação, a televisão é a que geralmente trabalha com um espectro mais amplo da noção de localismo. Ou seja, é muito mais comum se ter no jornal diário e no rádio um foco que priorize majoritariamente as pautas locais do que na televisão. Em suma, as redes nacionais de televisão trabalham basicamente com uma divisão bem clara em termo de regionalidades: nacional e internacional. Estruturalmente, há subdivisões regionais que, no caso do Brasil e dos Estados Unidos, implicam em priorizar as informações de âmbito estadual. E quando a notícia hiperlocal é trabalhada, ela ocupa parcialmente os espaços informativos da emissora. Mesmo se restringíssemos o corpus de estudo apenas aos canais de notícias 24 horas por dia, no Brasil não há o registro de nenhuma emissora com audiência significativa que trabalhe no formado hard news focando exclusivamente pautas locais. Chega-se, então, ao caso que será analisado no presente artigo: o canal de notícias hard news New York 1 (NY1). A emissora norteamericana, que pertence a Time Warner Cable, trabalha exclusivamente com pautas locais envolvendo os cinco bairros de Nova York: Manhattan, Broonklyn, Bronx, State Island e Queens. Como é abordado mais adiante, esse é o canal de notícias local mais antigo da Time Warner, tendo sido inaugurado em 1992.

A partir dessas considerações, o presente artigo problematiza a questão da relação entre telejornalismo e o local como critério de noticiabilidade a partir do caso da NY1. Para tanto, inicialmente será feita uma reflexão sobre a importância da proximidade geográfica como valor notícia no jornalismo e nos telejornais a partir da perspectiva de autores que trabalham a temática tanto em relação ao campo jornalístico, quanto ao televisual. Em um segundo momento, abordamos a relação entre local e global a partir da visão de HALL (2014) e de outros pensadores que refletem sobre o tema, tendo em vista 
que Nova York é uma cidade cosmopolita que reúne pessoas vindas de todas as partes do mundo. Após, é abordada brevemente a formação cosmopolita de Nova York. Por fim, analisamos a programação jornalística do NY1 observando como a emissora trata os assuntos hiperlocais em uma cidade global. Por fim, são apresentadas as considerações finais, provocando outros pesquisadores a seguirem debatendo o tema, afinal, por que cidades cosmopolitas brasileiras não contam com um canal de notícias hard news exclusivamente locais?

Responder a essa questão, não é o objetivo desse artigo. Também não vamos entrar em questões técnicas e econômicas relacionadas às diferenças existentes entre os canais brasileiros e americanos, mas sim, vamos refletir teoricamente sobre a presença das relações entre global e local no telejornalismo a partir do caso selecionado. Vale ressaltar ainda que, para as obras escritas na língua inglesa, optou-se pela tradução livre.

\section{O local como critério de noticiabilidade jornalístico}

Conforme já apontado por diversos autores e teóricos do jornalismo, os critérios de noticiabilidade que os jornalistas utilizam para definir o que é e o que não é notícia depende de uma série de fatores, dentre os quais, os empresariais. No entanto, tratandose de jornalismo, há alguns critérios que estão presentes em praticamente todos os veículos jornalísticos do mundo ocidental. Luhmann (2005), por exemplo, na sua análise sobre a realidade dos meios de comunicação, vai elencar dez critérios para a seleção das notícias: novidade, conflito, quantidade, relevância local, transgressões às normas, transgressões morais, personalidades, atualidades, manifestação de opiniões e utilidade. Sousa Pinto (2009), por sua vez, vai trazer alguns itens que convergem com a perspectiva citada anteriormente, e outros elementos novos. Para ela, para ser notícia a pauta deve atender a pelo menos um dos seguintes fundamentos: ineditismo, improbabilidade, utilidade, apelo, empatia, conflito, proeminência ou oportunidade. Traquina (2005), em sua abordagem sobre os critérios de noticiabilidade vai abarcar as mudanças e as variedades desses critérios ao longo do tempo, considerando períodos históricos e as regionalidades. No entanto, essa variação é muito pequena: "Iremos ver que o que foi notícia em três momentos históricos - os anos 70 do século XX, os anos 30-40 do XIX, e as primeiras décadas do século XVIII - para verificar que valores-notícias básicos têm variado pouco" (TRAQUINA, 2005, p.63). Ele trata os critérios de noticiabilidade como sendo os valores 
notícia compartilhados pelos jornalistas profissionais que formam o que ele chama de tribo jornalística.

A partir do levantamento de diversos autores, Traquina (2005) apresenta a sua tipologia: morte, notoriedade, proximidade, relevância, novidade, tempo, notabilidade, inesperado, conflito ou controvérsia, infração e escândalo. Como se pode perceber, analisando rapidamente os três autores citados, é possível observar que os critérios são bem semelhantes, mudando, em alguns casos, apenas a palavra utilizada para denominar um critério específico. O mesmo acontece em relação ao critério de noticiabilidade que interessa ao presente artigo: a proximidade geográfica. Como é fácil de perceber, esse critério aparece nas listas dos três autores citados, porém, com nomes variados. Assim como Traquina (2005), Luhmann (2005) e Pinto (2009), esse quesito vai estar em todas as listas sobre o tema justamente por ser um critério de noticiabilidade unânime por aqueles que integram a tribo jornalística. No entanto, para delimitar a presente abordagem, optouse por utilizar a perspectiva dos três autores já citados.

Inicialmente vale ressaltar as considerações de Traquina (2005). O autor ressalta que a proximidade é um dos principais critérios de noticiabilidade, porém, ele chama a atenção de que elas podem ser tanto geográficas quanto culturais. "Um acidente de viação com duas vítimas mortais em Cascais poderá ser notícia num jornal de Lisboa, e possivelmente, mas com maior dificuldade, num jornal do Porto, mas dificilmente num país estrangeiro" (TRAQUINA, 2005, p.80). Ora, podemos complementar que o geográfico passa a ser um fator legitimador e um critério de noticiabilidade muitas vezes subjetivo, afinal, como aponta Machado da Silva (2012), cidades, estados e países passam a ter uma polêmica atuação no sentido de legitimação da notícia, ou seja, é dada maior importância pelos canais jornalísticos para acontecimentos registrados nos grandes centros do globo. Criticando as dificuldades que os habitantes dos países abaixo da linha do Equador têm para conquistar reconhecimento global, o autor aponta a permanência desse fenômeno na contemporaneidade: "Mesmo na era da inteligência coletiva e do suposto fim da centralidade, os coletivos inteligentes situaram-se no alto do mapa, reterritorializando o planeta do conhecimento com uma metodologia vertical e intransponível" (MACHADO DA SILVA, 2012, p.56). Ou seja, basta se questionar por que para os jornalistas e as empresas jornalísticas a morte de cinco ou dez pessoas nos Estados Unidos ou em um país europeu é mais notícia do que a morte de centenas de 
moradores da África ou da Ásia. Tem-se, então, o fator geográfico no centro dos critérios de noticiabilidade. Porém, como esse não é o foco do presente estudo, fica a provocação para que outros pesquisadores aprofundem essa temática.

Sousa Pinto (2009), que tem longa atuação no jornal brasileiro Folha de S. Paulo, não utiliza nenhum sinônimo de proximidade geográfica em sua lista de critérios de noticiabilidade, no entanto, ele aparece incluído em outro item: "Utilidade: quanto mais pessoas possam ter sua vida afetada pela notícia, mais importante ela é" (SOUSA PINTO, 2009, p.60). Pode-se dizer que esse critério engloba a questão geográfica, pois ela está se referindo também às informações que envolvem trânsito, mudança de horário de atendimento ao público por parte das instituições públicas e privadas, políticas locais, problemas geológicos, climáticos ou ambientais que estão inseridos em um cenário geográfico, dentre outros.

Por fim, Luhmann (2005) vai utilizar o termo relevância local para definir um dos critérios de noticiabilidade. O autor justifica salientando que "no próprio lugar as pessoas sabem informar-se tão bem que qualquer informação adicional ganha importância" (LUHMANN, 2005, p.59). Além disso, certos acontecimentos apenas se tornam notícias em um âmbito muito estreito. "A distância precisa ser compensada pela gravidade da informação ou pela estranheza, ou pelo elemento exótico, que transmite ao mesmo tempo a informação de que tal evento dificilmente poderia ter ocorrido aqui" (Luhmann, 2005, p.60). A partir dessas três perspectivas, chega-se a seguinte questão: qual a importância desse critério de noticiabilidade para a televisão?

Primeiro, vale ressaltar que o modelo hard news vem do rádio norte-americano. Como ressalta Parada (2000), diversas emissoras de rádio utilizam uma programação voltada 24 horas para a notícia. "Com algumas variações, a emissora vai repetindo em determinado período de tempo as notícias mais importantes. Na medida em que o dia avança, os fatos novos vão superando os acontecimentos mais frios" (PARADA, 2000, p.123-124). Esse modelo, que chegou apenas mais tarde ao Brasil, foi adaptado pela televisão norte-americana com os canais de notícias 24 horas por dia. No Brasil, esse modelo passou a ser adotado por algumas grandes emissoras em seus canais de sinal fechado, tais como Globo News e Band News. Porém, como é abordado novamente mais adiante, não há no país um grande canal que trabalhe exclusivamente com notícias locais. 
Assim como acontece em outras plataformas, como no rádio e no jornal diário, o local também é um importante critério de noticiabilidade nos espaços noticiosos televisivos. Rudin e Ibbotson (2008) apontam que para se pensar os noticiários (boletins, notícias de última hora, noticiários diários, dentre outros) há o modelo regional. No entanto, eles abordam a questão da regionalidade apenas no que diz respeito ao noticiário, e não à emissora como um todo: "Em geral, o conteúdo de um noticiário regional segue a estrutura tradicional, na qual as notícias mais importantes e recentes da região são colocadas no início do programa" (RUDIN; IBBOTSON, 2008, PP.156). Ou seja, nesse caso a proximidade geográfica é um critério de noticiabilidade determinante para a seleção da pauta que se tornará notícia.

Aronchi de Sousa (2004), por sua vez, salienta que o noticiário é um dos principais formatos do telejornalismo, ressaltando que os critérios de noticiabilidade seguem, de modo geral, os mesmos que regem os profissionais do jornalismo, com a transmissão ocorrendo ao vivo. "Os principais telejornais continuam sendo transmitidos ao vivo, pois dão um tom de atualidade e permitem a realização de entrevistas em diversos pontos do país e do mundo" (ARONCHI DE SOUSA, 2004, p.152). Já no caso de um telejornal hiperlocal, os repórteres entram ao vivo direto dos bairros, como acontece no caso do NY1. Claro que, como destaca Squirra (1995), a televisão vai acrescentar outros critérios, como a qualidade da imagem, a narrativa a partir do vídeo e outros pontos que não serão aprofundados nesse artigo. Apesar disso, o mesmo autor salienta que o interesse do telespectador pelo que está acontecendo no lugar aonde ele está inserido é o mesmo do ouvinte de rádio ou do leitor do jornal diário:

O público da informação deseja, sempre que possível, saber o que se passa no lugar onde vive, no seu país e também no resto do mundo. Podemos informar que o público da televisão está aberto às informações e ao processo de comunicação das informações (SQUIRRA, 1995, p.48).

Mais adiante, quando o autor enumera os critérios de noticiabilidade para a televisão, a proximidade está mais uma vez pressente. "Notícia é o que acontece perto das pessoas alvo da audiência" (SQUIRRA, 1995, p.49).

Feitas essas considerações sobre a relação entre critérios de noticiabilidade e o local, no próximo capítulo são apresentadas reflexões sobre local e global. Isso é justificado pelo fato de que Nova York, a cidade onde está instalado o canal de notícias NY1, é uma cidade cosmopolita, mas que tem as suas particularidades locais. 


\section{Notas sobre a relação entre global x local}

A relação entre global e local sempre esteve no centro das discussões sobre a relação entre os meios de comunicação e a sociedade, inclusive nos já mencionados critérios de noticiabilidade jornalísticos. Obviamente, um estudo mais profundo sobre essa temática exigiria um espaço muito mais amplo, portanto, nesse capítulo são apresentadas apenas algumas considerações no sentido de contextualizar teoricamente a análise feita na última etapa desse artigo sobre o canal de notícias hard news norte-americano, NY1. Nesse sentido, optou-se pela abordagem apresentada por Hall (2014) sobre as relações entre global e local. Em uma de suas obras, o autor apresenta uma definição do termo globalização:

[...] a globalização se refere àqueles processos, atuantes numa escala global, que atravessam fronteiras nacionais, integrando e conectando comunidades e organizações em novas combinações de espaço-tempo, tornando o mundo, em realidade e em experiência, mais interconectado (HALL, 2014, p.39)

O autor complementa que a noção de globaliZação se distancia da ideia sociológica clássica que pensa na sociedade como "um sistema bem delimitado e sua substituição por uma perspectiva que se concentra na forma como a vida social está ordenada ao longo do tempo e do espaço" (HALL, 2014, p.39). Mesmo reconhecendo a influência e a existência do ciberespaço, apontado por Lévy (1999), não é aprofundada aqui a importância do mundo digital nessas alterações, afinal, elas já foram muito bem descritas e analisadas por diversos autores. Vamos nos restringir a síntese do autor francês, abordando o ciberespaço e a cibercultura: "O termo especifica não apenas a infra-estrutura material da comunicação digital, mas também o universo oceânico de informações que ela abriga, assim como os seres humanos que navegam e alimentam esse universo" (LÉVY, 1999, p.17). Ou seja, o cenário descrito por Lévy (1999), Hall (2014) e outros autores vai ser o resultado dessa relação entre o humano, a técnica e as vivências locais - geograficamente falando - da sociedade na sua relação com o global. Afinal, essa evolução tecnológica vai ainfluenciar o social: "Essas novas características temporais e espaciais, que resultam na compressão de distâncias e de escalas temporais, estão entre os aspectos mais importantes da globalização a terem efeito sobre as identidades culturais" (HALL, 2014, p.39). 
No entanto, essas relações não são tão simples assim. Em meio a isso tudo, há as relações econômicas, políticas e de poder que também influenciam essa sociedade globalizada, como bem apontou Barbero (2013). Afinal, todas essas matrizes sociais estão interligadas: "Hoje são sujeito/objeto de cultura tanto a arte quanto a saúde, o trabalho ou a violência, e há também cultura política, do narcotráfico, cultura organizacional, urbana, juvenil, de gênero, cultura científica, audiovisual, tecnológica, etc" (BARBERO, 2013, p.14). No caso norte-americano, e mais especificamente no caso de Nova York, ainda há a formação histórica, abordada novamente na análise, com a formação de diásporas de diversos povos e culturas das mais variadas partes do planeta. Ou seja, esses povos, como salienta Hall (2009), estão e não estão, de maneira simultânea, em suas casas. "Na situação da diáspora, as identidades se tornam múltiplas" (HALL, 2009, p.26). A partir dessa multiplicidade, há uma renovação no interesse pelo local.

Assim, ao invés de pensar no global como substituindo o local seria mais acurado pensar numa nova articulação entre "o global" e "o local". Este "local" não deve, naturalmente, ser confundido com velhas identidades, firmemente enraizadas em localidades bem delimitadas. Em vez disso, ele atua no interior da lógica da globalização. Entretanto, parece improvável que a globalização vá simplesmente destruir as identidades nacionais. É mais provável que ela vá produzir, simultaneamente, novas identificações "globais" e novas identificações "locais" (HALL, 2014, p.45).

Ou seja, não há uma morte do local, como alguns tendem a decretar empolgados pelas novas tecnologias e os fatores globalizantes. Tanto é que, no caso analisado, uma grande empresa midiátiva investe alto para a manutenção de um canal de notícias local na televisão, um dos veículos mais globais - principalmente com as suas extensões no mundo online - que estão inseridos na sociedade. Nesse sentido, ainda conforme Hall (2014), podemos destacar que a globalização segue caminhando conjuntamente com as identidades locais, mesmo não seguindo mesma lógica de espaço e tempo dos séculos anteriores. Aliás, o impacto da globalização nas culturas locais também não é determinista. A forma como acontece tal influência apresenta inúmeras variações.

Outro autor que reflete sobre as relações entre o global e o local é Maffesoli (2006). Em sua obra, o autor faz uma análise da substituição do individualismo - tão presente na cultura norte-americana dos anos 1960 e 1970 - para uma necessidade de identificação com um grupo no século XXI. "A metáfora da tribo, por sua vez, permite dar conta do processo de desindividualização, da saturação da função que lhe é inerente, e da valorização do papel que cada pessoa (persona) é chamada a representar dentro dela" 
(MAFFESOLI, 2006, p.31). Essa questão poderia ser aprofundada em outros estudos e aqui é mencionada para se entender o motivo que pode levar uma grande empresa a investir na manutenção de um canal de notícias hiperlocal. Ou seja, há uma hibridez entre a ideia de diáspora, de local transformado pelo global, e de pertencimento que os cidadãos (e imigrantes) de uma cidade como Nova York tem e que é reforçado pela presença de um canal de televisão hard news exclusivamente local.

\section{Nova York: uma perspectiva histórica}

Para que se entenda sobre o estilo global da cidade de Nova York é preciso voltar um pouco no tempo. Mais especificamente ao período de alta migração de europeus para o norte da América, principalmente a partir do século XIX. "O maior evento na história dos Estados Unidos foi a imigração em massa de pessoas vindas da Europa" (LUKACS, 2006, p.129). Tal processo alterou o caráter de nação dos Estados Unidos. Conforme Lukacs (2006), apenas em 1825 foram mais de 10 mil imigrantes entrando no país. O número saltaria para 100 mil em 1842, para 600 mil em 1881, para um milhão em 1905 e para mais de 32 milhões em 1920. Eram pessoas que encaravam viagens que duravam meses em barco a vapor até chegar ao outro lado do oceano. E quem eram essas pessoas? Eram homens e mulheres que viajavam para o novo continente com o mesmo objetivo de muitos que ainda seguem migrando para os Estados Unidos no século XXI: ascender economicamente e socialmente. "A ideia de uma terra fértil e abundante, um mundo imenso e a possibilidade de enriquecer a todos era um poderoso imã sobre essas massas" (KARNAL; PURDY; FERNANDES; MORAIS, 2011, p.44). Nesse cenário, a cidade de Nova York teve um papel central na história americana.

O processo de colonização, a exemplo do que ocorreram com todos os países do continente americano, fazia, por si só, que houvesse o encontro entre a cultura ocidental e a indígena. No caso de Nova York, os primeiros a colonizarem o lugar onde hoje é a ilha de Manhattan foram os holandeses, a partir de 1625. Assim, inicialmente o lugar onde hoje está uma das principais cidades do mundo passou a se chamar Nova Amsterdã. Apenas em 1664 é que a Holanda deixou a região para os ingleses, que mudaram o nome para Nova York. A partir de então, a cidade seguiu sendo um importante ponto de chegada de pessoas de todas as partes do mundo.

Um dos locais fundamentais para que os Estados Unidos e a cidade se tornasse tão eclética culturalmente foi Ellis Island, uma ilha que funcionou como centro de recepção 
REVISTA PAUTA GERAL

ESTUDOS EM JORNALISMO

10.5212/Revista Pa uta Gera I.v.3.i2.0006
面

PautaGeral

Estudos em Jornalismo

de imigrantes entre 1892 e 1954. Hoje, a história das pessoas que chegavam ao país é contada no museu que fica na referida ilha. Dados expostos no museu referentes ao ano de 1903, por exemplo, apontam que que das 951.227 pessoas que entraram nos Estados Unidos no referido ano, 700.113 ficaram vivendo na cidade de nova York. Ao mesmo tempo, o governo local adota políticas de nacionalização dos imigrantes. Na imagem a seguir é possível ver esse processo que envolvia crianças, filhos dos recém-chegados ao continente americano:

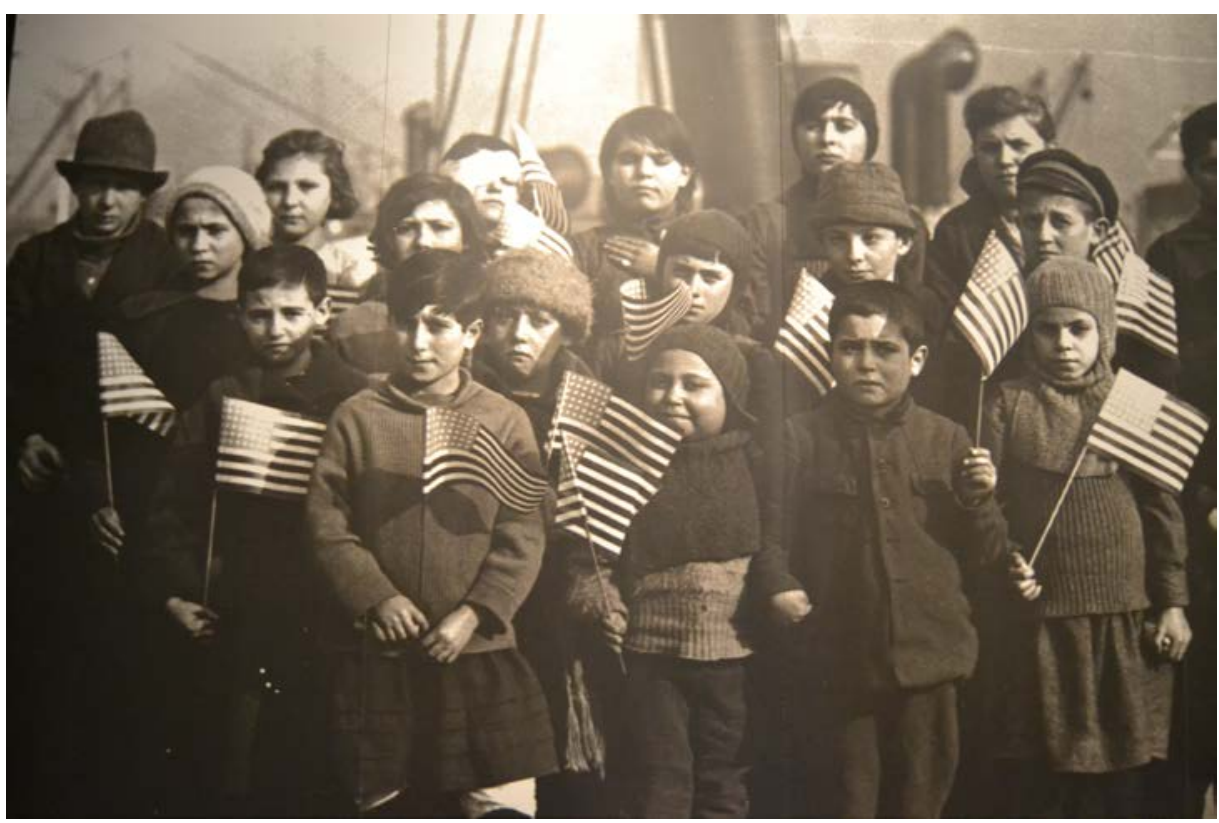

Imagem1: Crianças recém-chegadas da Europa no início do século XX pousam para foto com pequenas bandeiras americanas. Fonte: Ellis Island Immigration Museum, Nova York. Arquivo pessoal do autor.

Mais uma vez se tem a alegoria da diáspora de Hall (2009). Ou seja, essas pessoas que chegavam ao país na virada do século XIX para o século XX estavam longe de seus países de origem, porém, carregavam com elas as suas tradições, cultura, história e costumes. No entanto, tudo isso se hibridiza com o que está ocorrendo nos Estados Unidos, pois essas famílias, a exemplo do que aconteceu nos outros países da América, vão dar o caráter multicultural à nova nação.

Em Nova York esse processo é ainda mais acentuado, característica essa que permanece no século XXI com a chegada de milhares de imigrantes todos os anos. Porém, isso não acontece de forma tranquila ou sem conflitos, pois a diáspora está fundada sobre "a construção de uma fronteira de exclusão e depende da construção de 2016. 
um 'Outro' e de uma oposição rígida entre o dentro e o fora” (HALL, 2009, p.32-33). E essas questões também permanecem na contemporaneidade, principalmente no caso de Nova York, que segue recebendo imigrantes vindo de todos os continentes e das mais variadas culturas.

\section{NY1: um canal de notícias local em uma cidade global}

Foi já em meio ao contexto mencionado nos capítulos anteriores que surgiu em 1992 o canal de notícias local NY1. Essa foi a primeira emissora hard news a trabalhar exclusivamente com pautas locais, sendo pertencente a companhia de telecomunicações Time Warner Cable, que atua em 29 dos 50 estados norte-americanos. Conforme o site da companhia (http://www.timewarnercable.com/en/residential.html), depois do NY1, outras sete cidades também ganharam canais de notícias 24 horas, no já mencionado formato de programação que se assemelha ao do rádio norte-americano.

Além da emissora, que pode ser acessada no canal número 1 do sistema de televisão a cabo de Nova York, foi criado um site aonde são disponibilizadas as principais pautas que estão sendo veiculadas no formato televisivo (http://www.ny1.com/nyc/allboroughs.html). Para tanto, o foco principal das notícias é o que está acontecendo nos cinco grandes bairros da cidade: Manhattan, Brooklyn, Bronx, State Island e Queens. Como está destacado no site da emissora, e que também é ressaltado durante toda a programação diária ao vivo, assuntos como previsão do tempo, utilidades (mudança no horário de metrô, ônibus, etc.), crimes locais, temas polêmicos na política local, dentre outros, ganham destaque nos diversos noticiários. Ou seja, para atingir uma audiência tão diversificada, a emissora opta por trabalhar com informações que interessam a todos os moradores ou a todos os que estão na cidade, priorizando novidades relacionadas à utilidade pública local. Em outras palavras, independentemente da situação econômica, da classe social ou do país de origem do telespectador, ele sabe que vai encontrar lá informações relacionadas ao cotidiano da cidade e a sua funcionalidade.

O mesmo vale para a cobertura esportiva. Quando o esporte é abordado no espaço informativo da emissora, é apenas para tratar das equipes locais, tais como os times de basquete New York Knicks e Brooklyn, os times de baseball Yankees e Mets, os times de futebol americano Giants e Jets e o time de hockey no gelo, New York Rangers. O aberto de tênis US Open, competição que acontece anualmente na cidade no período 
REVISTA PAUTA GERAL

ESTUDOS EM JORNALISMO

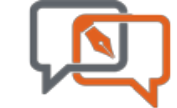

PautaGeral

Estudos em Jornalismo

de transição entre os meses de agosto e setembro, também ocupa espaço privilegiado na programação da emissora. Mas, mesmo sendo uma pauta global, ela é tratada sob a perspectiva local, com informações sobre horários de metrôs, acesso ao estádio, compra de ingressos, movimentação nos arredores do estádio, que fica no bairro do Queens, e outras informações que se enquadram no sentido de utilidade pública.

Para ficar mais claro como é organizado esse canal de notícias local em uma cidade totalmente globalizada, é imprescindível a observação de sua programação, disponível no site da emissora:

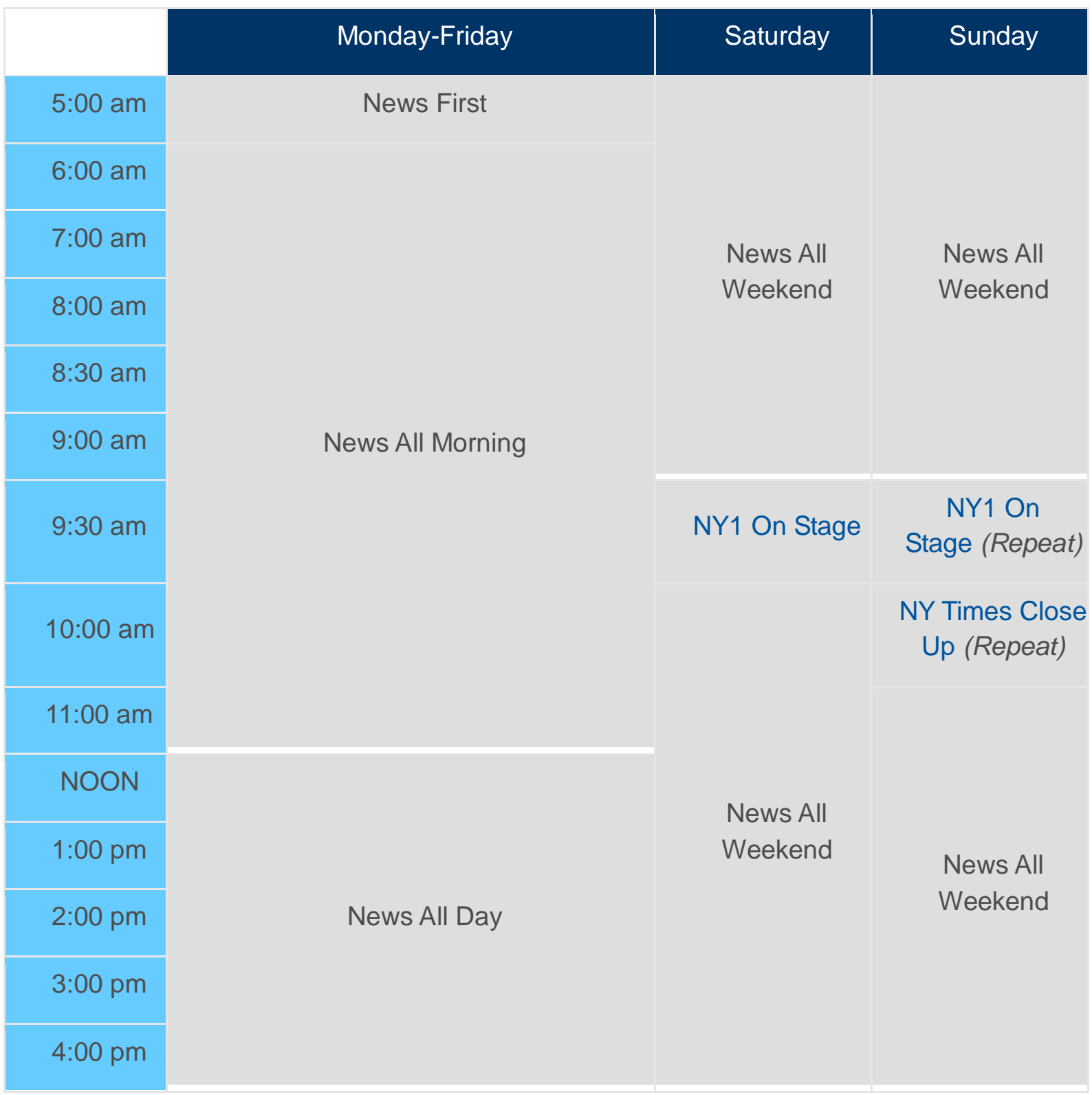

Revista Pauta Geral-Estudos em J omalismo, Ponta Grossa, vol.3, n.2 p.97-113 , J ul/Dez 2016. 
REVISTA PAUTA GERAL

ESTUDOS EM JORNALISMO

10.5212/ Revista Pa uta G eral.v.3.i2.0006

面

PautaGeral

Estudos em Jornalismo

\begin{tabular}{|c|c|c|c|}
\hline 5:00 pm & & & \\
\hline 6:00 pm & News All Evening & & \\
\hline $7: 00 \mathrm{pm}$ & \multirow[b]{2}{*}{ Inside City Hall } & & \\
\hline $7: 30 \mathrm{pm}$ & & $\begin{array}{c}\text { NY1 On } \\
\text { Stage (Repeat) }\end{array}$ & $\begin{array}{l}\text { NY1 On } \\
\text { Stage (Repeat) }\end{array}$ \\
\hline 8:00 pm & New York Tonight & \multirow{3}{*}{$\begin{array}{l}\text { News All } \\
\text { Weekend }\end{array}$} & \multirow{4}{*}{$\begin{array}{l}\text { News All } \\
\text { Weekend }\end{array}$} \\
\hline 9:00 pm & The Call & & \\
\hline 9:30 pm & $\begin{array}{c}\text { News All Evening } \\
\text { Mondays: NY1 On Stage (Repeat) }\end{array}$ & & \\
\hline $10: 00$ pm & Inside City Hall (Repeat) & $\begin{array}{l}\text { The New York } \\
\text { Times Close Up }\end{array}$ & \\
\hline $11: 00$ pm & News At Eleven & News At Eleven & News At Eleven \\
\hline $\begin{array}{l}\text { 11:35 pm } \\
\text { MIDNIGHT }\end{array}$ & Sports On 1: The Last Word & $\begin{array}{l}\text { Sports On 1: } \\
\text { The Last Word }\end{array}$ & $\begin{array}{l}\text { Sports On 1: } \\
\text { The Last Word }\end{array}$ \\
\hline $12: 30 \mathrm{am}$ & $\begin{array}{c}\text { News All Night } \\
\text { Tuesdays: NY1 On Stage (Repeat) }\end{array}$ & & \\
\hline $\begin{array}{l}1: 00 \mathrm{am} \\
2: 00 \mathrm{am}\end{array}$ & News All Night & $\begin{array}{l}\text { News All } \\
\text { Weekend }\end{array}$ & $\begin{array}{l}\text { News All } \\
\text { Weekend }\end{array}$ \\
\hline 3:00 am & The Call (Repeat) & & \\
\hline $3: 30 \mathrm{am}$ & News All Night & & \\
\hline 4:00 am & Sports On 1 (Repeat) & $\begin{array}{l}\text { Sports On } \\
1 \text { (Repeat) }\end{array}$ & $\begin{array}{l}\text { Sports On } \\
1 \text { (Repeat) }\end{array}$ \\
\hline
\end{tabular}

Como é possível perceber, a programação segue o mesmo modelo utilizado pelas emissoras radiofônicas de notícias hard news. As informações ao vivo começam a ser

Revista Pauta Geral-Estudos em J omalismo, Ponta Grossa, vol.3, n.2 p.97-113 , J ul/Dez 2016. 
transmitidas às $5 \mathrm{~h}$ da manhã com o programa News First que recupera os últimos acontecimentos do dia anterior e enfatiza informações de utilidade pública do dia que estão começando, como previsão do tempo, alterações no horário de linhas de ônibus/metrô e trânsito. O âncora também chama repórteres que estão espalhados pelos cinco bairros para fazer intervenções. A partir disso, a programação segue sendo noticiosa ao longo do dia, com os programas News all morning (notícias toda a manhã), News all day (notícias o dia todo) e News all evening (notícias a tarde toda). O formato só é quebrado entre as $19 \mathrm{~h}$ e as $19 \mathrm{~h} 30$, quando entra no ar o programa Inside the City Hall, com notícias sobre a prefeitura (e que é reprisado às $22 \mathrm{~h}$ ), e The call, que mais uma vez segue o modelo radiofônico: as notícias são comentadas por telespectadores que ligam para a emissora. Das $23 \mathrm{~h} 35$ até a meia-noite é apresentada uma síntese noticiosa esportiva em Sports on 1 (que é reprisado às 4h). As notícias seguem durante o restante da noite, com News all night (notícias a noite toda), que divide o espaço da programação com algumas reprises de programas que foram ao ar durante o dia.

A partir dessa programação, poder-se-ia analisar casos específicos de temáticas e notícias abordadas pela emissora. Em 2014, por exemplo, a morte de um homem negro, Eric Garner, de 43 anos, após ser preso por vender cigarros ilegalmente ocupou grande parte da programação televisiva da NY1. Como o homem era asmático e acabou morrendo após ser contido à força por vários policiais brancos (mesmo gritando que não estava conseguindo respirar) - e o episódio foi registrado por transeuntes e lançado na internet - houve uma mobilização popular no sentido de protestar contra a ação policial. Essa pauta ocupou o espaço noticioso e de debates - como em The call e em Inside the City Hall - durante os meses que se seguiram. Outra característica da abordagem noticiosa é o acompanhamento do desdobramento de casos como esse, da polêmica ação policial. Tal análise poderia ser feita, porém, necessitaria de um espaço mais amplo, podendo portanto, ser aprofundada em futuros estudos.

\section{Considerações finais}

A partir dos elementos vistos ao longo do artigo, como a proximidade geográfica sendo um dos principais critérios de noticiabilidade do jornalismo e as relações entre local e global, pode-se dizer que o canal de notícias hard news NY1 apresenta uma proposta de abordagem da cidade de Nova York que se diferencia das demais. Como foi ressaltado desde o início do presente estudo, essa é uma cidade essencialmente global e 
cosmopolita, com pessoas vindas de todas as partes do planeta. Tudo isso complexifica as relações entre a população nova-iorquina (formada tanto por americanos quanto por estrangeiros legais e ilegais) e a mídia. No entanto, reconhece-se que há um imaginário em torno de Nova York, reforçado pelo conteúdo midiático que circula por todo o mundo ocidental e oriental, que aponta a cidade como um lugar aonde não há nenhum vínculo com o local. Ou seja, há uma espécie de ilusão de que tudo em Nova York é transitório, de que tudo é espetáculo. No entanto, mesmo sendo uma cidade globalizada, existe a presença do local.

Buscando atender às demandas dos moradores de Nova York e de pessoas que passam por lá transitoriamente é que a Time Warner Cable criou o canal de notícias NY1. $\mathrm{E}$, para isso, defendemos a hipótese de que a proximidade geográfica é o principal critério de noticiabilidade da emissora, a exemplo do que acontece em muitas emissoras de rádio que trabalham no sistema de hard news. Assim, a emissora tenta deixar de lado as questões relacionadas ao global de suas pautas, colocando em primeiro plano o local, em uma tentativa de trazer a proximidade geográfica como um dos elementos de engajamento do telespectador, afinal, como aponta Maffesoli (2006), o indivíduo contemporâneo busca ingressar de alguma forma nas mais variadas tribos, sendo que a questão das regionalidades pode ser considerada uma das possibilidades de tribalização da sociedade. No entanto, tal relação, como foi visto, é complexa. Mesmo se tratando de notícias factuais e, muitas vezes, de utilidade pública, casos como a da morte de um morador negro de State Island traz à tona diversas questões culturais e políticas que perpassam a história, não só de Nova York, mas de todo o país. Racismo, preconceito contra imigrantes vindos dos países da parte de baixo da linha do Equador e outras temáticas aparecem na pauta midiática americana com certa frequência. Nesse sentido, os termos, a linguagem e o foco das matérias, acabam se tornando objeto de análise e de discussões, não só dentro dos Estados Unidos, mas em todo o mundo, afinal, essa é uma cidade global que recebe anualmente milhares de pessoas vindas de diversos países, dentre os quais o Brasil, que pretendem construir uma nova vida no hemisfério norte das américas.

Feitas essas considerações, ressalta-se novamente que o presente artigo teve como objetivo muito mais levantar pontos para serem discutidos futuramente e provocar reflexões do que apresentar respostas definitivas. Há diversas reportagens e temáticas 
abordadas pelo canal NY1 que poderiam ser discutidas diversos artigos, a partir da análise do discurso ou de outro método adequado. No entanto, nesse espaço se deu o primeiro passo, apresentando um contexto mais amplo, para que outros estudos mais específicos possam surgir futuramente. Aliás, repete-se mais uma vez a pergunta: já que o modelo brasileiro de fazer telejornalismo se inspirou tantas vezes nas matrizes norteamericanas, por que esse formato nunca ganhou espaço no Brasil? A diferença de acesso a TV a cabo - que apesar de ter aumentado no Brasil, ainda é bastante limitado na comparação com os Estados Unidos - é um desses fatores limitadores? O público brasileiro atenderia à proposta da emissora da mesma forma que o público americano atende? O formato hard News, para um canal de televisão local, é o melhor a ser utilizado? Essas e outras questões ficam em aberto para nortear futuras pesquisas desses e de outros estudiosos do jornalismo e da comunicação social.

\section{Referências}

ARONCHI DE SOUSA, J.C. Gêneros e formatos na televisão brasileira. São Paulo: Summus, 2004.

BARBERO, J.M. Dos meios às mediações - Comunicação, cultura e hegemonia. Rio de Janeiro: Ed. UFRJ, 2013.

HALL, S. A identidade cultural na pós-modernidade. Rio de Janeiro: Lamparina, 2014.

HALL, S. Da diáspora - Identidades e mediações culturais. Belo Horizonte: Ed. UFMG, 2009.

KARNAL, L.; PURDY, S.; FERNANDES, L.E.; MORAIS, M. História dos Estados Unidos - das origens ao século XXI. São Paulo: Contexto, 2011.

LÉVY, P. Cibercultura. São Paulo: Ed.34, 1999.

LUHMANN, N. A realidade dos meios de comunicação. São Paulo: Paulus, 2005.

LUKACS, J. Uma nova república - História dos Estados Unidos no século XX. Rio de Janeiro: Jorge Zahar Ed., 2006.

MACHADO DA SILVA, J. A sociedade medíocre - Passagem ao hiperespetacular (o fim do direito autoral, do livro e da escrita). Porto Alegre: Sulina, 2012.

MAFFESOLI, M. O tempo das tribos - O declínio do individualismo nas sociedades de massa. Rio de Janeiro: Forense Universitária, 2006. 
NEW YORK 1. Disponível em: http://www.ny1.com/nyc/all-boroughs.html Acesso em: 7 de junho de 2015.

PARADA, M. Rádio: 24 horas de jornalismo. São Paulo: Panda, 2000.

RUDIN, R.; IBBTOSN, T. Introdução ao jornalismo - Técnicas essenciais e conhecimentos básicos. São Paulo: Rocca, 2008.

SOUSA PINTO, A. E. Jornalismo diário. São Paulo: Publifolha, 2009.

SQUIRRA, S.C.M. Aprender telejornalismo - produção e técnica. São Paulo: Brasiliense, 1995.

TIME WARNER CABLE. Disponível em: http://www.timewarnercable.com/en/residential.html Acesso em: 5 de junho de 2015.

TRAQUINA, N. Teorias do jornalismo - Volume II: A tribo jornalística - uma comunidade interpretativa transnacional. Florianópolis: Insular, 2005.

Recebido em 14/07/2016

Publicado em 20/11/2016 